\title{
ESCRITA E CORPO E FABULAÇÃO: VARIAÇÕES COM DELEUZE E CLARICE LISPECTOR
}

\section{WRITING AND BODY AND FABULATION: VARIATIONS WITH DELEUZE AND CLARICE LISPECTOR}

\author{
Maria dos Remédios de Brito ${ }^{1}$ \\ Dhemersson Warly Santos Costa ${ }^{2}$
}

\begin{abstract}
Resumo: O ensaio é uma partilha das variações que atravessam a escrita, o corpo e a fabulação em Gilles Deleuze e Clarice Lispector. Ambos os pensadores mobilizam a escrita como um processo fabulatório que abre corpo para a experimentação de outras vidas, de mundos ainda não habitados. Questiona-se: Que ressonâncias seria possível entre Deleuze e Clarice? Que forças mobilizam a escrita, o corpo e a fabulação na literatura de Clarice Lispector? Que povo esse corpo-escrita expressa? É possível afirmar que para Deleuze, assim como para Clarice, a escrita faz nascer palavras, forjar linguagem, além de produzir um corpo a partir de seus vazios e fragmentos. Variações com Deleuze e Clarice, se não é uma aposta é uma invenção. Sigamos nesse processo de aberturas de mundos, de produzir modos de pensamentos outros, desenraizando o pensamento, a intuição para, então, poder criar um outro corpo-pensamento e uma outra forma de escrita.
\end{abstract}

Palavras-chave: Escrita; corpo; fabulação.

Abstract: The essay is a sharing of the variations that cross the writing, the body and the fabulation in Gilles Deleuze and Clarice Lispector. Both thinkers mobilize writing as a fabulatory process that opens the body for the experimentation of other lives, of worlds not yet inhabited. One wonders: What resonances would be possible between Deleuze and Clarice? What forces mobilize writing, the body and the fabulation in Clarice Lispector's literature? What people does this body-writing express? It is possible to say that for Deleuze, as for Clarice, writing gives birth to words, forges language, in addition to producing a body from its voids and fragments. Variations with Deleuze and Clarice, if it is not a bet it is an invention. Let us continue in this process of opening up worlds, of producing other modes of thinking, uprooting thought and intuition so that we can then create another body-thought and another form of writing.

Keywords: Writing; body; fabulation.

$*$

Quando estou escrevendo, eu simplesmente eu não sei como se escreve.

Clarice Lispector

O ensaio trata de uma escrita em que o corpo vai sendo atravessado pelo silêncio, pela dispersão, pelo impossível de interpretar, pela falta de significar palavras, pela impossibilidade de retratar, pois o corpo vai sendo cavado e esburacado por um indizível, um lugar em que o sentido se esvaia, restando ao corpo do leitor apenas se permitir ir pelos encontros, por entre as rasuras do texto, do seu não dito, do seu inacabamento. Esse é o corpo-escrita que se põe a desenhar nas linhas

\footnotetext{
${ }^{1}$ Professora da Universidade Federal do Pará, Belém-PA. E-mail: mrdbrito@ hotmail.com.

${ }^{2}$ Doutorando em Educação em Ciências e Matemáticas. Universidade Federal do Pará, Belém-PA. E-mail: dhemerson-santos@hotmail.com.
} 
dessa digressão, e toma como fio condutor o corpo entre escrita e fabulação, trançando entrelaçamentos entre a literatura de Clarice Lispector e as variações com a filosofia de Gilles Deleuze. Não há pretensão de promover um processo interpretativo da obra, do ato de escrever e do ato fabular de Clarice, mas dar ao pensamento outros encontros que ressoem literatura e filosofia.

A feitura dessa experiência é também alimentada por leituras da filosofia contemporânea de Gilles Deleuze, esse que tratou a literatura como um campo aberto da fabulação e do possível, abertura para o mundo, para um novo povo porvir. Não se trata de promover comparações, mas sentir um certo vento que sopra por esses pensamentos, um literário e o outro filosófico, ou melhor dizendo, que ventos deleuzianos sopram em Clarice? Deleuze põe a filosofia a pensar com as artes e as ciências, e diz que nenhuma poderia ser entendida como superior a outra, já que em seus lócus de produção cada uma é criadora. A filosofia cria conceitos, a ciência proposições e as artes perceptos e afectos. As artes criam blocos de sensações por meio de um campo de composição configurado pela palavra. A literatura, por meio da palavra, da linguagem e da escrita cria um povo, um por vir. Por isso que para Deleuze e Parnet (2004) a literatura é abrir, partir, se evadir, traçar uma linha de fuga, de modo que esse seria o objetivo mais elevado dessa produção artística, abrir o espaço para emergir uma outra vida. Clarice promove essa linha em sua obra literária, por isso tomaremos duas obras da autora para delas retirar essa fonte de abertura: A hora da estrela (1977) e Um aprendizado ou o livro dos prazeres (1998). Não há intenção de fazer qualquer análise literária e nem propor uma interpretação que esteja no campo de estudos especializados, pois não se trata de uma problemática referente à crítica ou aos estudos linguísticos de um texto literário. $\mathrm{O}$ trato com as obras diz respeito a ordem dos atravessamentos corporais intensivos. As obras literárias de Clarice Lispector afetam o corpo daquele que entra em contato com as letras e com as suas ideias, pois delas surgem um povo.

\section{$* *$}

Antes de aprender a ler e a escrever, eu já fabulava.

Clarice Lispector

Para Deleuze (2011), o escritor em seu processo inventivo atravessa um deserto, uma zona. Escrever é um exercício de desmontagem do corpo orgânico, do rosto, do nome. Esse exercício só é possível por uma função fabuladora que atravessa o ato de escrita e criação, pois "não há literatura sem fabulação" (DELEUZE, 2011, p. 14).

A fabulação é um conceito agenciado no pensamento filosófico de Gilles Deleuze que não é restrito a uma obra em particular, mas atravessa, pontualmente, diversos textos, compondo uma espécie de mapa. Assim, é possível encontrar o conceito de Fabulação em Crítica e Clínica (2011), O que é filosofia? (2010), Cinema II (2005) e em Bergonismo (1999a), associada à arte, em especial à Literatura e ao Cinema.

A fabulação trata de uma linguagem poética (literária e fílmica) que se afasta da perspectiva da narrativa - eis que esta é envergada pelas linhas da representação e da significação - ao se aproximar do campo dos afetos, dos encontros, daquilo que afeta o corpo e o desorganiza, arrastando-o para outras veredas, outros campos existenciais.

Fabular é se deixar afetar pelos encontros com a vida, com as forças que nos atravessam rotineiramente e nos arrastam para outros lugares, que instauram um caos interior, a nos provocar de tal forma que seja insustentável retornar para o lugar anterior, para o que se era. É se abrir aos encontros, deixar que algo passe, repasse, transpasse... que faça a vida se abrir em multiplicidades, na diferença. 
Escrever é um caso de fabulação quando o corpo daquele que escreve é afetado por forças, desejos e encontros capazes de mobilizar outros modos de existência. A escrita como abertura vital para mundos impossíveis; escrita como possibilidade de inventar vidas dissonantes, marginais.... Fabular é esse exercício de resistência, um exercício ético e político, como coloca Pellejero (2016), que dá passagens aos devires minoritários, às existências mínimas. Fabular é inventar um povo, um povo ainda por vir.

Fabular é criar linhas de fuga inventivas para não deixar cair na sedução da narrativa de si, engendrada no pensamento de representação e significação, uma "fabulação, uma função fabuladora que não seja imaginada nem projetada em um Eu. Ela atinge, sobretudo, essas visões, eleva-se até esses devores ou potências" (DELEUZE, 2011, p. 14), pois é um modelo de criação, de aliança em parceria com um produto que ainda não existe e por esse motivo, ainda pode ser inventado e / ou reinventado.

O elemento de fabulação é a invenção de um povo ainda por vir. Esse "ainda" não quer corrigir uma falta, uma falta ou incompleto, antes, trata de uma potência, uma força para produzir outra coisa, um processo de criação contínua do novo, um povo que está em movimento, pronto para abandonar o território. Uma função fabuladora da escrita que faz o mergulho no fundo do mar, onde tudo é devir e criar, e para criar é preciso navegar contra a corrente, chocar-se com as ondas (DELEUZE; GUATTARI, 2010).

A fabulação coloca em perspectiva um povo sem imagem, sem rosto, sem moral, um bando que nega os modelos identitários. O novo como força de resistência, que faz a vida transbordar de cheiros, perfumes, desejos, afetos. Um bando que atravessa o deserto e nele, onde "nada" existe, a vida floresce em multiplicidades, libertando-a das clausuras que nos aprisionam.

O flagrante delito da fabulação, no sentido deleuziano, reside na resistência como forma de criação de si e de novos modos de existência para além dos modelos que já estão dados. O delito de fabular uma vida que se faz nas fissuras, na resistência de uma micropolítica em aliança com a diferença, com a coletividade e com o abandono. A literatura enquanto função fabuladora deseja abandonar o território, inventar-se quantas vezes for necessário para existir, tencionar uma gagueira na língua, colocar as minorias em perspectiva. É fabulando que se inventa um povo menor.

Clarice Lispector desenvolve um modo de produzir sua poética de forma singular, atravessa o corpo do leitor com uma sensibilidade de quem nada pelas águas do humano em profundidade. Em seus escritos não deixa de colocar como destaque a sua forma de criação. Seus personagens são mapas abertos desse processo, toma como reflexão o ato de escrever como produção artística-vital e focaliza todo um campo de composição dessa arte por linhas corporais.

A escritora chega a uma espécie de fotografia sobre o ato de escrever, trazendo em detalhes a maquinação da escrita, ou seja, como surge uma ideia, como surge uma inspiração/intuição; a forma pela qual o seu corpo engendra a palavra e como a palavra vai tomando conteúdo e o que o corpo experimenta nesse processo de gestar a obra. Contudo, Lispector se coloca como uma escritora que caminha pelas bordas do não saber, reluta a se colocar como escritora profissional e reforça seu distanciamento do corpus da tradição literária e reivindica para si uma liberdade do ato de pensar e de escrever. Em diversos textos, a autora pontua uma escrita atravessada por cortes, em que as palavras perfuram o leitor diante do campo de composição de sua linguagem. 
Que forças mobilizam a escrita, o corpo e a fabulação na literatura de Clarice Lispector? Que povo esse corpo-escrita expressa? Para Lispector, escrever é uma necessidade vital do corpo - e não há outro motivo quando se fala de Clarice Lispector, seu corpo morria quando não exercitava o ato de escrever ${ }^{3}$. O que é vital para um corpo? Para a Biologia, o oxigênio, a água, a luz solar e o alimento funcionam como elementos vitais para a manutenção do corpo, a ausência de qualquer um destes impossibilitaria a vida. Aqui, porém, o corpo é pensado para além da perspectiva organicista. Assim, para este corpo, o estímulo é a própria vida em seu componente de abertura, implicando desejos, afetos, signos.... Tudo aquilo que o toca, que o arrasta para o deserto, que o estremece, acaba por produzir movimentos, deslocamentos, perplexidade, espanto, dor, agonia, alegria, horror, pois escrever para Lispector não era apenas uma profissão ou instrumento de autoconhecimento, mas era uma forma de estar no mundo, interagir com o mesmo, exercitar uma posição política diante da vida. O que é vital para esse corpo são os signos que o violentam, são os blocos de afectos e perceptos, estes, para Deleuze e Guattari (2010), são movimentos criadores proporcionados pela Arte e suas múltiplas variações: a literatura, o teatro, a música, o cinema, e outros. Nessa perspectiva, o ato de escrita é, também, o alimento para o corpo de Lispector, um corpo vivo afetado por uma necessidade demasiadamente irresistível de sentir o mundo, de habitá-lo por meio da palavra, essa que para Lispector era a tentativa de sentir, de dizer e de criar mundos.

Escreve-se com o corpo, diz Lispector "Eu não sou um intelectual, escrevo com o corpo. E o que escrevo é uma névoa úmida. As palavras são sons transfundidos de sombras que se entrecruzam desiguais, renda, música transfigurada de órgão" (LISPECTOR, 1977, p. 16). Por essas linhas escrever é uma necessidade vital, pois, segundo Deleuze (1999b, p. 3), "um criador só faz aquilo de que tem absoluta necessidade" (DELEUZE, 2011, p. 3), aquilo que o violenta, que arrasta o corpo em sua intensidade, que não tem nada de efetivamente pessoal, mas passa por todo um processo de dramatização da singularidade e dos encontros. $\mathrm{O}$ ato criador de Lispector era atravessado por uma força estranha, um impulso que movimentava seu corpo, pois como ela mesmo indaga: "Por que escrevo?... Escrevo, portanto, não por causa de uma nordestina mas por motivo grave de "força maior", como se diz nos requerimentos oficiais, por força de lei" (LISPECTOR, 1977, p. 16); "É nesse, sentido, pois, que escrever me é uma necessidade" (LISPECTOR, 1977, p. 155); "Quero apenas avisar que não escrevo por dinheiro e sim por impulso" (LISPECTOR, 1977, p. 1), diz ainda "Escrevo porque sou um desesperado e estou cansado, não suporto mais a rotina de me ser e se não fosse a sempre novidade que é escrever, eu morreria simbolicamente todos os dias" (LISPECTOR, 1977, p. 21). Dessa forma, a escrita se apresenta como resistência e desmontagem do corpo orgânico, instrumental, sendo a escrita um caso de experimentação, uma força que anima o corpo, desterritorializando-o e territorializando-o. Escrever é um exercício de fuga, pois como sustenta Lispector: "Quando não estou escrevendo, eu simplesmente não sei como escrever" (LISPECTOR, 1977, p. 25). Não há fórmula para o ato de escrever, não há receita antecipada, se aprende a escrever, escrevendo, deixando as palavras cortar a carne, atravessar o corpo, criar veias para deixar passar o sangue das palavras. Esse processo não remete ao dado, mas um constante movimento liberado pelo próprio ato de escrever, uma luta diária contra as codificações fixas ou, ao modo de Espinosa (1979), contra as paixões tristes, aquelas que enveredam o corpo para o seu declínio, para a escravidão de um corpo sem vida. Essa batalha que o escritor trava todos os dias, em prol de um corpo vivo, não é uma tarefa fácil, é doloroso desvencilhar-se dos estratos sociais, pois "Não, não é fácil escrever. É duro como quebrar rocha" (LISPECTOR, 1977, p. 19). Esse corpo que põe a trabalhar diariamente em prol de produzir um campo de sensações

\footnotetext{
${ }^{3}$ Ver entrevista dada pela autora a TV Cultura no link: https://www.youtube.com/watch?v=ohHP112EVnU.
} 
com a palavra, uma abertura com a linguagem nasce quando exercita o ato de criação e não sabe de antemão o que vem. Lispector faz do ato de escrever não só estético, mas ético.

Em Lispector, o ato de escrita e criação como um modo de vida, de entrar na vida. Escrever é um mergulho no mar profundo, onde o autor nadar contra a corrente, chocando-se com as ondas, afinal é na violência do encontro entre corpo e signos que o pensamento dá a pensar "A escrita, é uma violência, um rapto; é uma metamorfose dolorosa do corpo que contém uma soma de espiritualidade violenta e suscita uma aparente desordem extraordinária” (LINS, 2002, p. 67).

$\mathrm{O}$ ato de escrita é um encontro com a vida que passa pela experimentação de si e do/no outro, um movimento de variação contínua, um exercício de tornar-se outra coisa. Por isso, dirá Deleuze (2011, p. 11), que "Escrever é um caso de devir", uma pintura inacabada, uma passagem pela vida, um processo. Esse autor invoca a criança, a mulher, o animal, os grupos minoritários, pois escrever é entrar em zonas de vizinhanças com aquilo que foge aos grandes blocos molares: homem-adulto-heterossexual. Uma escrita-devir passa pela resistência à forma do homem e as suas classificações dicotômicas, libertando o corpo para criar outra prática de vida, ainda que nas palavras, o corpo do autor, que experimenta uma escrita-devir, torne-se uma dobra, inventando outros modos de existência, uma vida mais intensa.

Assim, o escritor potencializa o seu corpo vivo se misturando, através da escrita, com os estilhaços do animal $e$ da criança $e$ da mulher $e, e, e .$. Isso tudo para criar um possível, uma abertura no mundo, tomando a escrita como força política, pois "Não se brinca com a intuição, não se brinca com o escrever: a caça pode ferir mortalmente o caçador" (LISPECTOR, 1977, p. 28).

A escrita como expressão é política, é ética. Fabular não é brincar vulgarmente com as palavras e com a linguagem, fabular é construir formas de resistência a miserabilidade dogmática do mundo, ao inefável bloco duro de vida. Lispector remete essa questão em suas obras, tão qual a leitura Deleuziana sobre o ato de escrever-fabular.

A saúde como literatura, como escrita, consiste em inventar um povo que falta. Gilles Deleuze

Como se escreve desmontando os órgãos para abrir o fabular? O que Clarice Lispector pode nos ensinar com sua maquinaria do ato de escrever? O que se passa entre Deleuze e Lispector? A escrita solicita uma linguagem, assim como uma posição diante do mundo e diante daquele que exerce a arte de escrever como um modo de forjar meios, maneiras de pensar, de ser e de existir, daí seu posicionamento ético e estético.

Deleuze, amante da literatura, percorre a escrita que passa pela gagueira e pela linguagem que cria a variação. A escrita é vida e com ela é possível acionar os devires, mesmo os mais imperceptíveis. Lispector não receia em afirmar que escreve mobilizada pelo aberto, pelo impulso, em que as sílabas são cegas e os sentidos passam pelo corpóreo, sendo que o labor da poética passa por uma vibração e a palavra vem em sombras, em cores turvas, elas mudam de cor, de tom e de luz para desenhar um rosto de um povo.

Se a palavra pode ter o poder de libertar a imaginação, ela também abre o vazio, uma ausência, aquilo que nunca pode ser dito com medida, mas com sensações, pois a palavra foge de sua nomeação; a letra ao produzir palavra, ela aparece trêmula, fragmentada e turva, por isso o escrever é um caso de corpo e movimento, é um caso de desmontagem dos órgãos e dos organismos; escrever é libertar a vida das clausuras, promovendo uma experimentação com todos os sentidos, gerando um novo corpo, outra forma de entendimento com o mundo. Não é nada fácil escrever, pois 
perpassa por todo um processo de recolhimento, de escuta, de coletas de materiais, de estudo, de observação do mundo, de olhar aquilo que se chama realidade para então "pela límpida abstração de estrela do que se sente - capta-se a incógnita do instante que é duramente cristalina e vibrante no ar e na vida" (LISPECTOR, 1977, p. 10). Clarice Lispector nos ajuda a pensar quando questiona as regras, as normas, os enquadramentos, as formatações no ato de escrever.

Não se aprende a escrever por modelos pré-fabricados, escrever é ensaiar, repetir, tentar insistir, deixar passar a palavra que não vem inteira, a linguagem não fecha a comunicação. Há uma luta diária com a palavra, com o que deseja ser dito, a palavra corre, não se diz de um golpe só, escrever é labutar com os órgãos, fazer nascer um povo, é um ato de insistência, resistência. Lispector inspira aquele que lida com essa difícil arte de produzir um corpo com as palavras em que o "ato de escrever é como quebrar rochas" (LISPECTOR, 1977, p 19). O corpo percorre a maquinaria de algo que o atravessa e o deixa em espanto, a escrita passa por uma agitação, algo passa pelo corpo que não pode ficar internalizado como se a mesma solicitasse uma espécie de saúde. Nietzsche, em sua obra Ecce Homo (2003), afirma que foi no período de maior declínio de seus órgãos que ele estava com maior atenção para sua saúde. Escrever, para Nietzsche, passa pela vida e pela saúde. Escreve-se porque o corpo não aceita sucumbir aos poderes tristes. Na mesma esteira, Deleuze, coloca que escrever é um atletismo corporal, como se escrever fosse produzir uma saúde.

A escrita é uma forma de fazer o corpo se relacionar com as coisas, com os objetos, com o pensamento, com os sentidos. A escrita é uma máquina produtiva de fuga, porém fugir não é negar o mundo, ao contrário, é criar mundos possíveis, um povo por vir. Deleuze, amante da escrita e da literatura, afirma que escrever passa por uma clínica e uma crítica. Escreve-se porque algo atravessa o corpo, escreve-se porque o mundo nos espanta, escreve-se porque alguma coisa incomoda, diz Lispector que "Todos aqueles que fizeram grandes coisas, fizeram-nas para sair de uma dificuldade, de um beco sem saída" (DELEUZE, 2011, p. 47). Assim, a escrita é marcada por uma angústia, uma maquinaria de desfazer o organismo, em que há nesse desfazer a composição de outros órgãos por meio de uma coleta das existências mínimas, anotações em fragmentos, o silêncio povoado. Lispector em suas obras não deixa de falar do ato de escrever, fazendo o leitor sentir um corpo agitado, em que as palavras estão quase sempre por fazer. Ela fala dos seus gostos, dos seus passeios por entre pessoas, livros, galerias e leituras...

E chega a indicar que não há um tempo para escrever, o seu tempo de escrita é prolongado, deve ser cruzado por vários dispositivos que possam acionar o seu corpo, agitar o seu pensamento. Não se escreve sem agitação, pois "escrever o aprendizado é a própria vida se vivendo em nós e ao redor de nós" (LISPECTOR, 2010, s.p.). Aquele que escreve compõe seu próprio ato, inventa seu próprio aprendizado do tempo, assim como a sua própria língua.

Deleuze atravessa a literatura e outras artes, afirma em sua obra Crítica e Clínica (2011) que a literatura é vida. Ora, o que Deleuze quer defender em várias de suas obras é a necessidade de pensar uma outra forma de produzir a escrita não dogmática, passando pela invenção de um modo de expressão. A escrita deve desmobilizar os órgãos, descongelar o sangue que pulsa nas veias para criar outra língua. A literatura entra no pensamento de Deleuze para operar um modo de fazer filosofia, um modo de produzir um estilo, um pensamento que passe pela diferença. Para isso, é necessário compor também outro modo de fazer/pensar a escrita.

A escrita faz nascer palavras, forja a linguagem, para produzir um corpo a partir de seus vazios e fragmentos. Como máquina de desfazer os órgãos, a escrita exige do corpo, daquele que escreve, uma agitação dos órgãos para pensar, para abrir mundos possíveis, fazendo da escrita uma política da expressão.

Ora, em Clarice, não deixa de passar uma política, não deixa de passar uma minoria, uma posição no ato de escrever, não sendo somente um problema político da alma, mas de um povo, 
de um coletivo, de um agenciamento complexo de expressão. O povo e o escritor que se expressam em corpo e política se dão as mãos. Daí a invariante questão que Deleuze apresenta quando remete a fabulação como um problema de política de expressão. Lispector muitas vezes mostra em suas obras uma vergonha do mundo, uma vergonha do homem. Em o Mineirinho essa questão é claramente posta, fazendo o seu leitor se confrontar com essa vergonha que deve ser sua, deve ser de cada homem, pois como diz Lispector "E arte, imagino, não é inocente, é tornar-se inocente" (LISPECTOR, 2010a, p. 71). Ora, o que seria torna-se inocente na perspectiva de Lispector? Arriscaremos a pensar: é ser capaz de olhar o mundo, sentir a vida, perceber seus jogos, driblar seus horrores para fazer nascer outro mundo no qual o homem seja capaz de viver. A literatura assume seu papel de fabular outros mundos, outras realidades, outras vidas possíveis quando se torna inocente no sentido fundamental do termo.

...vou lentamente me encaminhando - e também para o quê, não sei. De um modo geral, para mais amor por tudo. É vago "mais amor por tudo? " Inclusive mais amor inclui uma leveza maior para achar o bonito o que nem mesmo bonito é. E, embora a palavra humana me arrepie um pouco, de tão carregada de sentidos variados e vazios essa palavra foi ficando, sinto me encaminhando para o mais humano. Ao mesmo tempo as coisas do mundo - os objetos-estão cada vez mais se tornando importante para mim. Vejo os objetos sem quase me misturar com eles, vendo-os por eles mesmos. Então às vezes se tornam fantásticos por eles mesmos e livres, como se fossem coisas nascidas e não feitas por pessoas... (LISPECTOR, 2010a, p. 75).

Nesse processo, a expressão habita uma autonomia, tomando em mãos sua própria eficácia imersa em um campo de composição ao qual o contexto dialoga com as impossibilidades, ou seja, "a palavra pescando o que não é palavra" (LISPECTOR, 2010b, p. 95) para então se confrontar com a vida que nasce, com a fabulação que se cria. Essa não seria a inocência do escritor?

$* * * * *$

Fabular diz respeito a mais íntima política de expressão que não deixa de abrir também as (im)possibilidades. Clarice constrói uma lente de aumento em A hora da estrela (1977) para mostrar um corpo vivo, dissecado pelo mundo dos homens. Macabéa, jovem alagoana de 19 anos, órfã, não tem quase lembranças dos pais que morreram quando ela era criança, sendo criada por uma tia, religiosa, cheia de tabus, além do seu moralismo. A tia parecia que tinha prazer em dar cascudos sem motivos na sobrinha. Passou uma infância infame, sem afeto, sem cuidados, sem conforto. Vai para o Rio de Janeiro com essa tia que parece ser seu único parente. A jovem não tem estudos, ainda assim, fez um curso de datilografia e consegue um emprego neste ofício, ganhando menos que um salário mínimo.

A tia morre, Macabéa vai para uma pensão e divide um quarto com 4 balconistas. Seu corpo cheira mal, toma banho raramente, tem insônia, pois tem uma tosse, azia, tomava muito café frio e comia pedaços de papel para enganar a fome. Busca evitar ou conviver com a solidão por meio da escuta de um programa de rádio em um aparelho de uma amiga. A Rádio Relógio dava a hora, fazia propaganda e a transmitia informações vazias, sem instrução ou teor de esclarecimento, ficava a querer traduzir certas palavras. Macabéa também buscava colar recortes de revistas e jornais que colecionava em um álbum. Magra, faminta, se alimentava de cachorro quente, seu luxo era pintar suas unhas de vermelho e, quando recebia seu salário, ia ao cinema. Sonhava ser uma estrela de televisão, era seu maior sonho, ela que ainda se dava ao direito de sonhar... 
Com uma amiga do trabalho aprende a criar desculpas e um dia diz para o seu chefe que vai retirar um dente e falta ao trabalho para aproveitar a liberdade de fazer coisas diferentes. Assim que as colegas saem do quarto, ela coloca música, dança, toma café.... Ela ri, se olha, sente seu corpo, sua existência. Sai de casa e neste dia conhece Olímpico de Jesus, seu primeiro e único namorado, um metalúrgico sem caráter. $\mathrm{O}$ passeio dos dois eram programas gratuitos. Macabéa fazia uma série de perguntas para Olímpico. Ele, por sua vez, não suportava tantos questionamentos, pois isso o colocava em enfrentamento com sua ignorância, por isso, reclamava e ela sempre pedia desculpas, porque apesar de Olímpico não lhe oferecer carinho, a jovem queria sua companhia, tal sua solidão, seu desamparo.

Clarice coloca no final dessa obra a personagem principal na presença de uma cartomante que revela um destino de esperança - ela se casará com um estrangeiro rico. Macabéa, emocionada com o seu destino, sai correndo, distraída, não olha ao atravessar a rua e é atropelada por um carro. Uma multidão olha aquele corpo estendido no chão e não faz nada, ele, lá permanece. Uma cena que confronta o leitor com sua vergonha, com a sua barbárie.

$\mathrm{O}$ que se poderia retirar dessa obra como linha de fuga? A literatura fazendo abrir o mundo, a criar um povo por vir? Onde Clarice faz aparecer por meio do corpo da nordestina sofrida, corpo jogado no mundo, uma abertura de um povo por vir? Como ter uma epifania diante de tanto horror? Macabéa diante de todo seu horror, condenada à morte prematura por não ter condições econômicas e materiais, nem mesmo um suporte educativo, carrega em seu corpo o espanto, a capacidade de admiração, de não saber, de não ter ressentimento do mundo, embora tivesse todas as condições para ter, do mesmo modo que Clarice impõe ao leitor a seguinte indagação: O que de Macabéa me faz ver em meu corpo? Qual miséria posta no corpo de Macabéa que habita em mim? O que posso fazer para criar um outro mundo em que uma Macabéa deixe de existir? O que de Macabéa pode ser conservado e elaborado? Macabéa, vida infame, mas também vida que desejava um outro povo, quando fazia seu processo de existência resistência, pela simples abertura de movimentar o ato de pensar, de perguntar e de sonhar em um mundo quase impossível de viver. Clarice diz para o seu leitor que a literatura se aproxima da filosofia quando ambas persistem no modo de produzir o pensamento. Macabéa pensava e desconsertava com suas perguntas, seu questionamento de criança em que o mundo ainda é novo, ainda posto a ser criado, que povo minoritário surge por meio do corpo de Macabéa?

O corpo aparentemente morto de Macabéa promove a linha de fuga porque não se deixa instrumentalizar pela vida infame que lhe foi imposta. Toma o ato de perguntar, de se espantar com o mundo, sua abertura para a vida. Há desejo que lhe permite sonhar e fazer, aparecer uma linha no horizonte, uma linha não é sair do mundo, esconder o rosto, cobrir o corpo para não receber a luz, não é entrar no campo místico ou algo parecido, se acovardar perante a vida, escapar dos engajamentos sociais, políticos. Não promover uma renúncia sobre as ações, também fugir é ao "contrário do imaginário" (DELEUZE; PARNET, 2004, p. 30), mas fugir é criar um movimento, fazer um sistema abrir seus vazamentos, mas "Fugir é traçar uma linha, linhas, toda uma cartografia. Só se descobre mundos através de uma longa fuga quebrada" (DELEUZE; PARNET, 2004, p. 30). Clarice faz essa linha de fuga aparecer em sua literatura. Ela apresenta rupturas, personagens descobridoras de mundos, Lori, por exemplo, Uma aprendizagem ou o livro dos Prazeres (1998), faz todo um processo de aprender pelo desaprender, ao mesmo tempo em que Clarice destaca que o aprender tem ligações com o amor, o amoroso faz nascer mundos, mas não é nossa intenção desenvolver essa questão aqui. $\mathrm{O}$ corpo de Lori é atravessado pelo amoroso. Lori não aprende o que o professor de Filosofia, Ulisses, ensina pelo seu campo de racionalidade, ao contrário, Lori aprende quando o seu corpo é tocado por signos emitidos pelo professor, quando pelos encontros com esse homem aprende sobre si, sobre a vergonha de ser mulher, sobre o medo de não saber o que pode uma mulher pela potência do seu corpo, pois 
mesmo o que é ser uma mulher? Ou o que seria estar preparada para mundo? Que maturidade é essa exigida por Ulisses? Pelo o que passa ser maduro? O que seria racionalizar as sensações, os desejos? O aprender passa muito mais pelo não saber do que pelo saber, nos ensina Clarice, do mesmo modo que esse aprendizado não forma ligações com a intelecção, mas com o corpo. Diz Lori "Aprender contigo, mas você pensa que eu aprendi com leituras, porque não foi, aprendi ou você nem sonhava em mim aprender" (LISPECTOR, 1998, p. 157). Ora, como aprender o que não foi ensinado, esse aprender que não foi conduzido? Só pode ser um aprendizado que passa pela singularidade, pelo encontro com os signos. Essa terra para aprender, fazer com que essa mesma terra possa abrir processos de resistência ao mundo instrumental. Assim, Clarice, pelo homem, pelas suas lacunas, pelas suas desordens, pelo seu não saber, deixa atravessar pelo corpo, pela escrita e pelo fabular uma rachadura. Agora, em Clarice, se existe uma literatura raiz ou a mesma uma árvore, um campo de registro, isso é a leitura de cada leitor, pois esta afirma que há nos seus escritos operações de cortes significativos e criação de um povo porvir.

$* * * * * *$

A literatura está antes do lado do informe.

Gilles Deleuze

O ensaio não compara os autores, antes deseja fazer passar sons em uma temática cara para ambos. A escrita faz nascer palavras, forja a linguagem, para produzir um corpo a partir de seus vazios e fragmentos. Como máquina de desfazer os órgãos, a escrita exige do corpo, daquele que escreve, uma agitação dos órgãos para pensar e fabular. Variações com Deleuze e Clarice se não é uma aposta é uma invenção, sigamos nesse processo de aberturas de mundos, de produzir modos de pensamentos outros, desenraizando o pensamento, a intuição para, então, poder criar um outro corpo e uma outra forma de escrita.

\section{Referências}

DELEUZE, G. Bergsonismo. São Paulo: Editora 34, 1999a.

DELEUZE, G. O ato de criação. Folha de São Paulo, v. 27, p. 4, 1999 b.

DELEUZE, G. Cinema II. São Paulo: A\&C Black, 2005.

DELEUZE, G. Crítica e Clínica. São Paulo: Editora 34, 2011.

DELEUZE, G; GUATTARI, F. O que é filosofia? São Paulo: Editora 34, 2010.

DELEUZE, G; PARNET, C. Diálogos. Lisboa: Relógio dágua, 2004.

ESPINOSA, B. Os pensadores. São Paulo: Abril, 1979.

LINS, D. A metafísica da carne: que pode um corpo. In: LINS, D.; GADELHA, S. (Org.). Nietzsche e Deleuze: que pode um corpo. Rio de Janeiro: Relume Dumará, 2002. p. 67-80.

LISPECTOR, C. A hora da estrela. Rio de Janeiro: Livraria Francisco Alves, 1977. 
LISPECTOR, C. Uma aprendizagem ou o livro dos prazeres. Rio de Janeiro: Rocco, 1998.

LISPECTOR, C. Aprendendo a viver. Rio de Janeiro: Rocco, 2010a.

LISPECTOR, C. Crônicas para jovens: de escrita e vida. Rio de Janeiro: Rocco, 2010b

NIETZSCHE, F. Ecce homo: de como a gente se torna o que a gente é. São Paulo: L\&PM, 2003.

PELLEJERO, E. Literatura e fabulação: Deleuze e a política da expressão. PolymatheiaRevista de Filosofia, v. 4, n. 5, p. 61-79, 2008. 